'Krishnamurthi, V., Nayudu, S. G., and Nath, M. C., Proc. Soc. Exp. Biol. and Med., 117,861 (1964).

Nath, N., Yawalkar, V. D., and Nath, M. C., Nature, 208, 1001 (1965). 'Artizzu, M., Baccino, F. M., and Dianzani, M. U., Biochim. Biophys. Acta,
78, 1 (1963).

10 West, E. S., J. Biol, Chem., 74, 561 (1927).

11 Nath, M. C., Chitale, R. P., and Belavady, B., Nature, 170, 545 (1952).

${ }^{2}$ Nath, M. C., and Nath, N., Ind. J. Med. Res., 53, 1010 (1965).

1o Schneider, W. C., and Hogeboom, G. H., J. Biol. Chem., 183, 123 (1950).

14 Fiske, C. H., and Subba Row, Y.. J. Biol. Chem., 66, 375 (1925).

\section{Conversion of $\delta$-Amino Laevulinic Acid to Porphobilinogen by Different Tissues of the Polychaete Annelid Neoamphitrite figulus}

The heart-body, a small spongy mass of tissue within the dorsal vessel of the terebellid polychaete Neoamphitrite figulus (Dalyell), is almost certainly concerned with synthesis of the haemoglobin of the blood. The coelomocytes also contain haemoglobin, but this is different. Kennedy and Dales' have shown that the heart-body tissue and the coelomocytes in this species converted porphobilinogen (PBG) to uroporphyrin. Tissues were incubated with purified PBG suspended in sea water and at room temperature for varying periods and the products identified after extraction and purification by paper chromatography. Some similarly performed experiments using $\delta$-amino laevulinic acid (ALA) did not give clear results. Subsequent work, using the method of $\mathrm{McRae}^{2}$, whereby the conversion of ALA to PBG is identified against suitable controls by the positive reaction $\mathrm{PBG}$ gives with Ehrlich's $p$-aminobenzaldehyde reagent ${ }^{3}$, has, nevertheless, given quite clear results. McRae's method was followed in detail except that to quantify the results the tissues were merely dried with acetone and weighed, for it was desired only to compare the relative ability of different tissues to convert ALA to PBG. McRae used homogenates of whole animals (Dugesia). Tissues were deep frozen and homogenized on thawing in $M / 15$ phos-

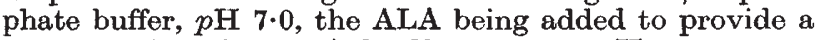
concentration of $400 \mu \mathrm{g} / \mathrm{ml}$. of homogenate. Homogenates, suitably controlled, were incubated at $37^{\circ} \mathrm{C}$ for $2.5 \mathrm{~h}$. The colour of the Ehrlich reaction was measured at $553 \mathrm{~m} \mu$ after $15 \mathrm{~min}$ with a 'Unicam SP 500' spectrophotometer. While the activity of each tissue is expressed in arbitrary units, their relative activities in one typical experiment are shown in Table 1. The experiment was repeated five times with similar results. The tissues of five worms were pooled in each experiment. Table 1 shows that the heart-body is ten times more active than any other tissue determined. The body wall muscle is colourless and if it contains any myoglobin this is in a relatively low concentration and any ALAase present is insufficient to produce enough PBG to be detected by the method. On the other hand, Kennedy and Dales ${ }^{4}$ detected coproporphyrin III, which must have been formed during haem synthesis, in the body wall; whether this is formed in the skin or is deposited there, as this negative result suggests, is being investigated further. The hind stomach or gizzard has muscles of a deep red colour and some ability to convert ALA to PBG is not surprising. The ability of the coelomocytes to do so is

Table 1. CONVERSION OF ALA TO PBG BY DIFFERENT TISSUES OF Neoamphitrite figulus

$\quad$ Tissue
Heart-body
Coelomocytes
Fore stomach + intestine
Hind stomach (gizzard)
Body wall
Blood

Weight of
tissue
(mg)
$1 \cdot 8$
$\mathbf{6 4 . 9}$
$39 \cdot 6$
$58 \cdot 0$
$177 \cdot 5$
$7 \cdot 9$

Activity

8900

$89 \cdot 00$

$8 \cdot 50$
$7 \cdot 82$

$7 \cdot 82$
$4 \cdot 08$

$\mathbf{4} \cdot 08$
$0 \cdot 00$ (arbitrary units/ also expected, confirming the hypothesis that they synthesize their own haemoglobin from ALA and do not receive compcunds later in the biosynthetic pathway to haem. The high activity of the gut (fore stomach plus intestine) from which the contents had carefully been removed is surprising, especially because Kennedy and Dales $^{4}$ found no free porphyrins in these tissues. It may be that the coelomocytes, which contain haemoglobin, arise from the coelomic epithelium of the gut wall. This is being investigated further.

I wish to thank Miss Jennifer Pell for collecting the specimens used.

Department of Zoology,

R. Phillips Dales

Bedford College,

University of London.

Received December 14, 1967.

'Kennedy, G. Y,, and Dales, R. P., J. Mar. Biol. Assoc. UK, 48 (in the press, 1968).

McRae, E, K., J. Exp. Zool., 142, 607 (1959).

${ }^{3}$ Mauzerall, D., and Granick, S., J. Biol. Chem., 328, 1141 (1958),

${ }^{4}$ Kennedy, G. Y., and Dales, R. P., J. Mar. Biol. Assoc. UK, 37, 15 (1958).

\section{Measurement and Significance of Weight Heterogeneity in Some Protein and Polysaccharide Preparations}

Most of the molecular weight values reported for macromolecules have been obtained by methods based on ultracentrifuge measurements. Many biologists and biochemists now have access to an analytical ultracentrifuge and their requirements can be satisfied by sedimentation velocity experiments.

Although macromolecules may sediment at similar rates and produce sharp boundaries, it is sometimes forgotten that this does not necessarily imply homogeneity of the system. Thus serum transferrins produce a single sym. metrical boundary in ultracentrifuge experiments whereas under electrophoresis the proteins may be resolved into two or more discrete fractions, depending on the animal species. The transferrins may also exhibit some degree of association, for reported molecular weights of the trans. ferrins $^{1,2}$ of several species are between 66,000 and 90,000 . The discrepancy in the reported molecular weights is of some clinical importance because it affects the reliability of iron binding measurements. Polysaccharides such as glycogen and amylopectin produce sharp boundaries as a result of the very large concentration dependence of the sedimentation coefficient ${ }^{3}$. These polysaccharides possess a very broad distribution with respect to sedimentation velocities. Several methods have been proposed in the past twenty years for the quantitative measurement of weight heterogeneity. In 1944 , Gralén ${ }^{4}$ proposed that the width of the sedimenting boundary was an index of heterogeneity. More recently, Baldwin ${ }^{5,6}$ and other workers have made detailed analyses in which the complete distribution curve of the sedimentation coefficients is evaluated (compare Schachman ${ }^{7}$ ). Other more basic factors are often ignored, regardless of the method selected for quantitation of heterogeneity. Quite often the criteria of purity applied to the preparation are not sensitive enough to justify detailed mathematical analysis of the boundaries. The preparations may also undergo physicochemical changes during the experiment ${ }^{8}$ so that control experiments are essential.

We have been studying changes in the catabolic heterogeneity and weight heterogeneity of serum $7 S$ gamma globulins in mouse and man after immunization with various antigens, including malignant tumours. Electrophoretically distinct fractions of $7 S$ gamma globulin are broken down at different rates in the mouse ${ }^{8,10}$ and signi- 